Fecha de recepción: marzo 2020 Fecha de aceptación: abril 2020 Versión final: mayo 2020

\section{La Forestal en clave fílmica. Un pasado que no termina de pasar}

Daniel J. Imfeld ${ }^{(1)}$

Resumen: El accionar en el chaco austral y el norte santafesino de la compañía inglesa "The Forestal, Land, Timber and Railways Company limited" (1906-1969) -conocida más popularmente como "La Forestal"- generó profundos impactos ambientales y sociales con consecuencias que trascienden hasta el presente. El tema, ha sido abordado en distintas producciones; desde la literatura que devino en registro historiográfico (Gori; 1965) a las producciones fílmicas, que abarcan documentales y ficciones como la recordada película Quebracho (Wullicher: 1974). Este trabajo se propone realizar un seguimiento de dichas producciones para focalizar en el análisis de Viaje a la Tierra del Quebracho (Quiñones: 2011), un corto de animación que presenta un pasado histórico complejo y con consecuencias en el presente.

Palabras clave: La Forestal - producciones fílmicas - memoria - despojo - significados

[Resúmenes en inglés y portugués en las páginas 44-45]

(1) Profesor de Historia, Licenciado en Gestión de Instituciones Educativas y Diplomado en Historia Pública y Divulgación Social de la Historia (UNQ) Miembro del Centro de Estudios e Investigaciones Históricas de Rafaela. (C.E.I.H.R)

\title{
Introducción
}

"La Forestal" es la manera como se conoció a la empresa inglesa "The Forestal, Land, Timber and Railways Company Limited", dedicada a la explotación de los bosques de quebracho colorado en el chaco austral, y particularmente en la provincia de Santa Fe, con el objetivo de la obtención de tanino. La presencia de la empresa deparó en una acción depredadora de los recursos naturales y de explotación laboral, por lo que se convirtió en un caso particular de un fenómeno económico y social más complejo. Nos referimos a la organización de la producción a escala mundial, con las consecuencias implicadas por su instalación en el territorio, así como las que se derivaron de la posterior retirada. 
Las memorias encontradas recorren todavía ese espacio con sus propias construcciones narrativas, entre quienes creen haber vivido un tiempo de bonanza, asociado con la acción patriarcal de la empresa, y los que no olvidan las formas de la violencia con las que se buscaba controlar y disciplinar los cuerpos de los trabajadores. Esto llamó la atención de los que se propusieron denunciar y/o historizar aquellos acontecimientos; desde diversos espacios se trató de desentrañar la estructura causal de los relatos de memoria, y esto significó la multiplicación de narrativas construidas en diversos formatos.

Documentalistas y cineastas revisitan dicha historia, recrean los hechos acontecidos, se posicionan desde diversos compromisos políticos, y recorren un presente que no puede despojarse de la nostalgia de unos y de la falta de expectativas de otros; van tras un imaginario de pueblos fantasmas en los que campea la amenaza de la pérdida de memoria. En estos relatos se repiten tópicos como la depredación de la riqueza natural, la explotación del recurso humano en beneficio de un capital internacional, que al ver finalizado el ciclo extractivo se retira y produce una situación de abandono. Sujetos sociales anónimos, sacrificables ante una realidad que con el paso del tiempo no logra revertirse. Los textos fílmicos, a manera de anticipación de una hipótesis, dan cuenta de los modos de concebir, sentir y otorgar sentidos a esta historia y al espacio-territorio de los pueblos forestales. Se impone así una representación de explotación, abandono y pérdidas que se inscriben en el cuerpo social y en las subjetividades, atravesadas por dichas situaciones.

\section{La historia que se (re)presenta}

La construcción historiográfica sobre la presencia de la compañía inglesa en el chaco santafesino reconoce un antecedente de gran peso, la obra del escritor Gastón Gori La Forestal. La tragedia del Quebracho Colorado (1965). Concebida como un ensayo, prácticamente en el momento en que la empresa se estaba retirando, marcó un camino en cuanto a la interpretación histórica de lo sucedido en aquel escenario. Un texto que, según recuerda el propio autor, surgió en principio, del encargo de una editorial que pretendía una novela, y terminó constituyendo un estudio que puso en escena los intereses de una empresa, los sucesos trágicos relacionados con su accionar (como las huelgas de la década de 1920), la creación de la gendarmería volante y la feroz represión, así como los efectos negativos de la explotación latifundista; en pocas palabras, la herencia que había dejado todo aquello. De ahí aquella sentencia con la que finalizara su obra: "El panorama del latifundio oprime de soledad al hombre argentino y en las grandes rutas, a uno y otro costado, yace la tierra de los latifundios. La Forestal no es la única. El país está enfermo de latifundios" (Gori, 1969, p. 252).

La influencia del relato de Gori no pasó desapercibida y es posible advertirla en varios los documentales que se realizaron desde entonces, así como en la película de Wullicher, Quebracho (1974).

En general, las historias narradas focalizan su trama en el tiempo de la empresa inglesa, que va desde su instalación en 1906 hasta el cierre de la última de sus fábricas en La Gallareta, en 1963 (aunque las oficinas comerciales dejaron de funcionar en Santa Fe en el año 1969). Sin embargo la explotación forestal reconoce un pasado anterior del que poco se da cuenta, pues unas décadas antes de la instalación de la compañía inglesa, se había 
iniciado la explotación del quebracho con otras firmas de capitales europeos (franceses y alemanes). Este pasado se comenzó a complejizar con aportes como el de Jasinski (2013) que lo abordó desde lo que denominó Régimen social de La Forestal.

El autor trata de echar luz acerca de otros aspectos que hicieron a la vida de los pueblos forestales; amplía las fuentes consultadas para dar cuenta de cómo la empresa se convirtió en rectora y dominante de la vida social, económica, cultural y política de aquella región. Da cuenta del proceso mediante el cual la compañía inglesa clausuró el espacio regional, profundizó algunas características anteriores y creó otras nuevas, configurando un régimen que no tardó en ser cuestionado. Primero con medidas aisladas y acciones prescindentes, y finalmente a fines de la década de 1910 por activos sindicatos que corporizaron sus demandas en un único y poderoso sujeto: la Forestal.

Para entender a La Forestal -como fenómeno social, sobre el que dirigen sus miradas tanto las producciones historiográficas como las fílmicas-, es necesario dar cuenta del referente territorial. No sólo la empresa inglesa se instaló en el chaco santafesino en la cuña boscosa, sino que "produjo" ese espacio, es decir, le dio una nueva vida, lo organizó según sus leyes, dirigió y tuvo bajo su control el proceso de formación de ese territorio. Cabe señalar, que no se trata de un escenario neutro sobre el que se montó una escena en la que se desarrollaron unos determinados sucesos, sino de un territorio con características propias que contenía un recurso altamente valorado en su momento: el quebracho colorado. La explotación empresarial de ese recurso natural modificó los rasgos naturales propios del paisaje original a partir de la tala de los bosques, y generó uno nuevo, que implicó la construcción de pueblos, fábricas, caminos, cisternas para el almacenamiento de agua, líneas telegráficas, ferrocarriles, puertos. Tras el fin del ciclo económico extractivista, constituyeron marcas de un pasado sobre las que la memoria hace su trabajo.

\section{Las construcciones fílmicas a lo largo del tiempo}

La revisión de una serie de materiales fílmicos que se fueron desarrollando en distintos momentos en torno de esta temática, permite aproximarnos a cuestiones referidas a la historización de un proceso y su localización geográfica, para pensar desde allí los motivos. Esto nos abre a algunas cuestiones que nos pueden servir de guía: ¿cómo se fueron desarrollando los motivos?, ¿cuáles fueron los intereses a lo largo del tiempo?, ¿hubo continuidades, se dieron cambios?, ¿se trata en sí de la construcción/representación de un cronotopos del despojo?

Un mojón necesario, antes de la visita a los documentales sobre el tema, es el referido la película Quebracho (Wullicher, 1974). Desde una mirada comprometida políticamente, centrada en el conflicto y la lucha obrera, se convierte en un caso único de abordaje de La Forestal como referente histórico desde el cine. Como el mismo director lo manifestara: "Queríamos hacer una película que recordara cómo son los esquemas de explotación colonial de los países del primer mundo sobre los emergentes y dar a entender qué es un esquema de expoliación planificado. A propósito, porque a mí me parece que esta lucha aún continúa no le puse la palabra fin." (Wullicher, 2014). Siguiendo a Rosenstone (2017) podemos decir que se recrea aquí el pasado como drama y como documento, organizando 
el desarrollo de la trama en tres períodos o momentos según el relato histórico guionado: 1913-1920 / 1930-1940 / 1945-1963.

El propio Ricardo Wullicher, entonces con 24 años se convirtió en uno de los directores más jóvenes al momento de la filmación con la responsabilidad de dirigir a un elenco que contaba con la presencia de actores de la talla de Héctor Alterio, Lautaro Murúa, Juan Carlos Gené, Cipe Lincovsky entre otros. Wullicher intervino también en la redacción del guion, junto con José María Paolantonio y bajo la supervisión de Paco Urondo. En ese momento coincidía con otra película que ponía en escena el drama de la explotación y represión de las luchas obreras, nos referimos al film de Olivera, La Patagonia Rebelde (1974). Enmarcada en el debate contemporáneo de las relaciones centro-periferia como denuncia del sistema de explotación de los países centrales sobre los periféricos, la película puede ser abordada desde su capacidad de agencia, al tiempo que no deja de mostrar a la distancia, el coraje de su rodaje, ya que se hizo bajo las amenazas de la violencia política desatada en aquellos años. Lejos de tratar la historia a la manera hollywoodense, en este filme, se piensa las geografías del Tercer Mundo, y se representa lo ocurrido, así como algunos de los significados otorgados en su momento (años 70). De esta manera el filme, interroga al pasado respecto de ese presente, recreando un mundo complejo y conflictivo. Retomando las representaciones de no ficción, y como lo afirma Plantinga, el documental articula afirmaciones sobre el mundo a partir de una postura asertiva: "Una película de no ficción afirma o sugiere que el estado de cosas presentado ocurre en el mundo real como es representado" (2014, p. 125). De allí que resulte como guía imprescindible para su análisis atender a los parámetros generales del "modelo mundo" del documental de acuerdo con lo que plantea el citado autor. Según el mismo cabe entonces seguir las estrategias que se ponen en juego en el discurso de no ficción, que van de lo que se selecciona, al orden y la estructura, así como el énfasis, la voz implícita en el discurso o actitud hacia lo que se representa.

De la amplia lista de audiovisuales sobre el tema, referiremos a algunas producciones: Quebracho Colorado (1953), documental para Sucesos Argentinos, La Forestal y sus Pueblos (2015) Las Grandes Huelgas de La Forestal para la serie Los Trabajos y los Días (2017, Canal Encuentro), La Forestal para La Otra Historia (2018, Canal á), y La Ruta de La Forestal (2019). Para nuestro trabajo, elegimos ampliar el análisis del corto de animación Viaje a la Tierra del Quebracho (2011).

Quebracho Colorado (1953), estuvo destinado a ser difundido a través de Sucesos Argentinos; se presenta como un "Film documental sobre la fuente primordial de la industria tánica del país", como anuncia el texto sobreimpreso en su inicio. Ubicado en el contexto de la Argentina del primer peronismo, se puede reparar en su condición de documental de propaganda política, donde la preocupación del enunciado estaba puesta en construir desde lo visual una representación del trabajador - obrero forestal - asociada a su condición de fuerza generadora de la riqueza nacional. Las imágenes registradas en los escenarios naturales de la geografía chaqueña bien parecen responder a la idea del cuerpo total de la nación territorial, que al peronismo de entonces le preocupaba difundir como sitio de identificación geográfica, más allá de las tradicionales locaciones fabriles en los suburbios de Buenos Aires. En esa geografía cobra forma una visión del obrero del país profundo, con el que se pretende fundar el tipo argentino arraigado en lo más hondo del sentir de la 
tierra, caracterizado por su fortaleza, su nobleza, su reciedad física. Las imágenes, que van de la fuerza bruta, afectada a la tala en los montes, al proceso productivo en las fábricas; los primeros planos que se posan sobre los cuerpos, parecen confirmar la supremacía étnica del criollo que trasciende su espacio natural. La voz en off en relación con el carácter expositivo del documental, actúa como la voz de Dios (Plantinga, 2014) tratando de ofrecer verdades desde una posición de autoridad. Con un tono firme, de exaltación, asume una actitud implícita hacia lo que se representa, confirma y resalta el lenguaje visual en pos del discurso de reivindicación de la clase trabajadora y la dignificación del obrero en ese presente. Quedan lejos, ocluidos, los conflictos por la explotación pues no hay referencias al pasado. El documental presenta una unidad ideológica y proporciona un modelo de identificación y un referente moral asentado en valores como el sacrificio, el esfuerzo, el trabajo, orientados todos al progreso colectivo y el amor a la patria.

La serie de producciones documentales construidas posteriormente, inspiradas muchas de ellas en los aportes del ensayo y la historiografía ponen al descubierto la historia de la empresa La Forestal. Parten de una concepción ideológica crítica sobre el pasado y el modelo de desarrollo económico derivado de la inserción de Argentina dentro de las relaciones internacionales del capitalismo. Desde el punto de vista narrativo abordan de lleno el proceso histórico del que pretenden dar cuenta, concatenando situaciones en las que tuvieron lugar los acontecimientos y en las que aparecen los personajes situados en sus ambientes específicos, los pueblos forestales. El recurso al archivo (fotografías y filmaciones de época) les otorga verosimilitud a los relatos acompañados generalmente de una voz formal que asume un alto grado de autoridad epistémica (personificada en historiadores o expertos en el tema) mediante las preguntas que tratan de responder a través del desarrollo, por lo que no solo ofrecen explicaciones sino que arriban a conclusiones rotundas. Documentales como Las Grandes Huelgas de La Forestal (2017), con guion de Mariano Llinás y Alejo Maguillansky, y contenidos e investigación de Jorge Halperín y Paula Halperín; o el capítulo La Forestal, para La Otra Historia, con guion de Alejandro Ansotegui, destacan, a través del discurso, la depredación de la riqueza natural sobre la base de la explotación del trabajador en beneficio del capital foráneo. Sus argumentos dan cuenta de cómo se generó la lucha sindical a través de una serie de huelgas violentamente reprimidas. Se presenta así una historia de explotación, de pérdidas, en escenarios de abandono, que configuran una cronotopía del despojo. Esto se escenifica en un paisaje arrasado producto de una expoliación, con sujetos subalternizados (hacheros, peones, obreros de las fábricas) cuyas memorias moran en -lo que hoy para el imaginario son- pueblos fantasmas.

Las pérdidas, lo perdido, se constituye en eje. Esto se refuerza con la selección de imágenes y puestas en escenas que privilegian la exposición de las ruinas de las fábricas, de las viviendas que delatan el paso de los años, de calles casi desiertas, de chimeneas que ya no sacan humo y que se presentan como foco sobre el que las cámaras hacen permanente zoom. Una metáfora que ratifica la clausura de un ciclo.

A la hora de poner una voz, junto al discurso del experto (historiadores, periodistas, comunicadores) se recurre al testimonio como recurso fundamental, a las voces de los que quedaron, como sonidos de fondo de un tiempo detenido, junto con el sonido de los pájaros y el silencio de las fábricas. A su vez, mediante la puesta en cuadro expresiva, los rostros de quienes son entrevistados, muestran el estado de melancolía, tristeza en que se 
encuentran. Los primeros planos dan cuenta de miradas que se dirigen hacia un horizonte lejano, cargado de añoranzas. Así el imaginario de pueblos fantasmas se torna en verosímil a través del referente fílmico tanto en su dimensión visual como sonora.

La estructura dramática y narrativa de estos documentales se basa en la rememorización del pasado que se va a buscar en esas geografías. En esa búsqueda, más allá de los testimonios encontrados, se recurre, para llenar los vacíos, a representaciones icónicas tales como las viejas fotos de archivos, los restos de objetos, máquinas ferroviarias abandonadas, fábricas desmanteladas que permiten evocar el referente, los tiempos de La Forestal. El relato de la tragedia del quebracho, que de manera pionera anunciara Gori, parece así instalado en el horizonte mental de los lugareños y de quienes se acercan a registrar documentalmente esas imágenes.

Desde otro posicionamiento, en este caso como reportaje antropológico que forma parte de un proyecto de la Universidad Nacional de Rosario, La Forestal y sus Pueblos introduce la presencia y la voz del especialista, Cristina Pasquali, que recorre los pueblos en función de una tarea de relevamiento relacionada con su estudio. Aquí preocupa el trabajo de deconstrucción y recuperación de la memoria, con especial interés en los jóvenes que asisten a la escuela secundaria. Se trata de la generación que no vivió los tiempos de actividad febril, pero que creció en un entorno de desarraigo y con una carga negativa sobre el pasado. Más allá del binarismo con el que se encuentran a la hora del testimonio de los mayores, fue bueno/fue malo según el lugar que ocupó cada uno en aquel esquema, la cámara busca, lo particular, lo singular que en el presente se puede reconocer en la población.

No menos interesante resulta lo que afirma Piedras (2010), cuando sostiene que el documentalista como el historiador es el encargado de descubrir, seleccionar y organizar un material que precede al proceso de creación audiovisual, esto aplica también al espacio seleccionado. En La ruta de La Foresta (2018) nos encontramos con un grupo de jóvenes realizadores que, a través del personaje (encarnado por Justo Benedetto) que se presenta como: "yo soy Tito, tengo 18 años, soy de Santa Fe" inscriben un YO adolescente en el discurso fílmico. Esto resulta provocador en relación con los actores sociales representados (los habitantes de los pueblos forestales, ex trabajadores, un ingeniero agrónomo, una maestra), la provocación se extiende a las entrevistas, entre las que se incluyen la realizada a un Osvaldo Bayer, muy mayor; en la misma se evidencia lo que experimenta el personaje, a través del movimiento de la cámara y de los aspectos subjetivos del discurso, la espontaneidad, el lenguaje juvenil y el énfasis en las dimensiones afectivas, crece a medida que el personaje de Tito, descubre en sus recorridos el pasado de La Forestal.

Este audiovisual, que fue pensado para un público adolescente de entre 14 y 17 años, decide incluir, -al igual que otras versiones documentales- escenas de filmes, a la manera de fuentes históricas que sirven para ratificar el verosímil. De esta manera, fragmentos de Hachero Nomás (Patricio Coll, 1966), de Quebracho Colorado (1953) y de Quebracho (Wullicher, 1974), forman parte del relato. La experiencia y la percepción del personaje de Tito, resulta conmovida a medida que avanzan estas imágenes y la investigación, y el objeto del relato resulta resignificado al ser atravesado por esta mirada joven fuertemente subjetivizada. 


\section{La mirada desde un corto de animación}

Nos detendremos aquí en Viaje a la Tierra del Quebracho (Quiñones, 2011). Se trata de un corto de animación que narra, en clave fantástica los hechos sucedidos en relación con los pueblos forestales del norte santafesino y que puede pensarse al servicio de la memoria y de la identidad (Ferro, 2017). En palabras del director: "Surge de la necesidad de recuperar una historia que está cayendo en el olvido. A tal fin, la idea es que sirva como punto de partida, no es un material educativo en sí, sino una ficción.” (Quiñones, 2011).

El corto se inicia cuando un niño de la ciudad, convocado por un sueño revelador y motivado por su curiosidad "Cuando era chico, me preguntaba qué habría al final de la vía", comienza un viaje hacia la tierra forestal. Siguiendo el camino que le marcan las vías muertas del ferrocarril, emprende la odisea infantil guiado por Guala, el espíritu protector del quebracho, quien le aclara "Este no es tu tiempo". A lo largo de la trama, va descubriendo los sucesos históricos que ocurrieron en los dominios de La Forestal, desde la penosa vida de los hacheros, el desplazamiento de los pueblos originarios, el accionar de la empresa explotadora, la reacción obrera, hasta terminar en el juicio, al que finalmente es llevado por la conjunción de intereses que se vieron afectados; en esta instancia se le acusa de haberse metido en asuntos privados y se lo declara culpable.

En el relato, se mezclan, la trama ficcional y la historia, en esta última, prevalece la versión que contó Gori (1969), la de la tragedia del quebracho, la de la frontera verde, un impenetrable que contenía una riqueza que debía ser explotada. Por su parte, la estructura dramática permite reconocer varios enunciados que van desde la explotación laboral al desastre ecológico, la lucha sindical, el poder empresarial. En ese contexto los personajes devienen en arquetipos antagónicos: el explotador extranjero versus los explotados criollos. Lo cierto es que este colectivo, es delineado de forma más compleja, pues tiene capacidad de transformarse, lo que se advierte, en el pasaje de ser mano de obra subalternizada a sublevarse contra las condiciones de trabajo impuestas. Los criollos, explotados, fuerza bruta de trabajo, son representados como puro cuerpo que dan paso a la mente al momento en que se sublevan. Frente a ellos el extranjero, explotador, ordena el mundo, dirige, da órdenes, esclaviza. El trabajador criollo no es un sujeto en ese mundo, ha sido desplazado desde otras regiones (correntinos, chaqueños, paraguayos) para ser introducido allí por la fuerza de un sistema de explotación; se convierte así en un signo ícono, el trabajador explotado. Se vuelve significante del régimen social del que hablara Jasinski (2013), que resulta funcional a la construcción del relato audiovisual. Más allá de este antagonismo, el verdadero antagonista, -que se constituye en tema del cortometraje-, es la pérdida de memoria que amenaza a las generaciones más jóvenes.

Las voces como instrumento de agenciamiento cobran presencia cuando los obreros se convierten en personajes políticos, protestan, queman las instalaciones, son reprimidos. La expresividad está puesta en el dibujo, los diálogos son muy breves. La banda sonora ambienta escenas referidas a la empresa, con ritmos urbanos, el cancionero chamamecero, asociado con el Litoral, para las escenas donde el monte y los hacheros son prota- 
gonistas y las referencias musicales étnicas para la presencia originaria, desplazada de su ambiente natural. Algunos sonidos ambientes enmarcan determinadas escenas, el chillido de un guinche abandonado, los grillos en la noche.

La puesta en cuadro recurre a la repetición de ciertos elementos. Las figuras definidas como siluetas, para el caso de los trabajadores, se pueden relacionar con lo de seres anónimos, cosificados, en tanto sus explotadores, aparecen portando elementos visuales con los que se suele asociar a personajes representativos del capitalismo, como el detalle de los sombreros de copa. El binarismo en el discurso se hace presente a su vez en lo de explotador / explotados, capitalismo / expoliación, centro / periferia, ambición económica de la empresa / riqueza espiritual personificada en el espíritu guardián del quebracho.

En relación con la producción estética, según lo manifestaron los propios realizadores, se trató de dar un enfoque local, se dibujó cuadro por cuadro pintando cada fotograma a mano pero en digital: "Primero se hacían los cuadros claves, luego los cuadros intermedios, luego se sombreaba y finalmente se coloreaba a los personajes. En algunas tomas hay más de diez personajes en escena, por lo que teníamos que planearlos muy bien. Los fondos fueron pintados a mano, en acrílico sobre cartón, y también tuvieron un retoque digital. También hay elementos 3D que debieron ser modelados, texturizados y animados." (Quiñones, 2011).

Del análisis se desprende que la paleta se desplaza desde los tonos más brillantes para el mundo forestal virando a los más oscuros para el trabajo fabril y las revueltas. El color, tan importante en este tipo de acercamientos, marca también las diferencias en las siluetas de los personajes, claras para los trabajadores, grisáceas para la fuerza de control y represión que actuaba al servicio de la empresa, que en sus sombreros y como brazaletes llevan un distintivo rojo, identificatorio de los tristemente apodados cardenales.

Si bien se basa en la técnica del dibujo animado tradicional, una característica a señalar, que coloca a esta producción y su divulgación social en un lugar destacado en relación con la cultura libre, es que además de la licencia utilizada para su distribución, la producción se realizó enteramente utilizando un software libre que se adaptó para responder a las necesidades del proyecto y pensando en llegar a la mayor cantidad de público posible Para finalizar, cabe señalar que es la metáfora del viaje la que estructura el relato. Se trata de un viaje de descubrimiento, el tren, es también "tren de la Historia", que recorre el paisaje de un pasado que no se quiere olvidar. El llamado a partir, a transitar por un camino caído en el abandono, es también una incitación a la recuperación de la memoria.

La distancia del niño con ese pasado adquiere entonces una dimensión espacio-temporal, en la que se enlaza el hilo intergeneracional. Se intenta, de este modo, disparar una serie de interrogantes que van más allá del mero acontecimiento, preguntas a las que volver una y otra vez, acerca del sentido más profundo del pasado, acerca de si es posible a la distancia sentir alguna pertenencia o empatía hacia aquello que no hemos vivido, de lo acontecido en un tiempo que no es el nuestro. Para preguntar entonces, hasta qué punto nos seguimos identificando con esta historia y si es posible cambiarla 


\section{Bibliografía}

Bordwell, David (1996). "Capítulo 9: La narración clásica”, en La narración en el cine de ficción, [en línea]. Disponible en: https://www.academia.edu/3689566/BORDWELL_David_La_narración_en_el_cine_de_ficción

Ferro, Marc (2017). "Perspectivas en torno a la relación historia-cine", en Ramaletti, La escritura fílmica de la Historia: problemas, recursos, perspectivas, capítulo 1, páginas 1947, Sáenz Peña, Universidad Nacional de Tres de Febrero.

Gori, Gastón (1969). La Forestal. La Tragedia del Quebracho Colorado. Rosario: Ameghino Editora.

Jasinski, Alejandro (2013). El Régimen Social de La Forestal en sus primeras décadas. Condiciones de vida en el Chaco Santafesino (1900-1920), [en línea]. Disponible en https:// ri.conicet.gov.ar/bitstream/handle/11336/26616/CONICET_Digital_Nro.b886a2d76968-475a-b756-83364d9c0922_B.pdf?sequence=5\&isAllowed=y Consultado el 22 de febrero de 2020.

Pécora, Pablo (2014). Ricardo Wullicher y la vigencia de "Quebracho" a 40 años de su estreno, [en línea]. Disponible en https://www.telam.com.ar/notas/201403/55003-ricardowullicher-y-la-vigencia-de-quebracho-a-40-anos-de-su-estreno.html

Piedras, Pablo (2010). El problema de la primera persona en el cine documental contemporáneo. Modos de representar lo autobiográfico en ciertos documentales latinoamericanos, [en línea]. Disponible en http://www.interdoc.org/projecte/2_ESTRUCTURA_CONTINGUTS_INTERDOC/5_RECURSOS/1_GENERE_DOCUMENTAL/NOVES_TENDENCIES/CINE_AUTOBIOGRAFIC/cine_autobiografico.pdf

Plantinga, Carl (2014). Retórica y representación en el cine de no ficción, capítulo 5, páginas 121-138 y capítulo 6, páginas 143-158, México: Universidad Nacional Autónoma de México.

Caracterización y ética en el género documental en: http://cinefagos.net/ index.php/documentos/442-el-travelling-de-kapo

Ramaletti, Mario (2017), La escritura fílmica de la Historia: problemas, recursos, perspectivas, 1. ${ }^{a}$ ed. compendiada, Sáenz Peña: Universidad Nacional de Tres de Febrero.

Rosenstone, Robert (2017). "El pasado en imágenes", en Ramaletti, La escritura fílmica de la Historia, 1. a ed. compendiada, capítulo 2, páginas 43-64, Sáenz Peña: Universidad Nacional de Tres de Febrero.

Viaje a la Tierra del Quebracho en www.creativecommons.org.ar > article > se-estrena-yse-libera-el-corto-via...

\section{Referencias filmográficas}

Quebracho Colorado (1953) https://youtu.be/5zPTg4iSG-A

Quebracho (Wullicher, 1974) https://youtu.be/EJwEljkr25w

Viaje a la Tierra del Quebracho (Quiñones, 2011) https://youtu.be/EJwEljkr25w

Las Grandes Huelgas de La Forestal (2017), https://youtu.be/mkNnaGz3UpM 
La Forestal, para "La Otra Historia” https://youtu.be/AEs-UHq9HZE

La Forestal y sus Pueblos https://youtu.be/-L_1YVrQL3U

La ruta de La Forestal (2018) https://youtu.be/7s7T8dnVLRQ

Ficha técnica:

Título: Viaje a la Tierra del Quebracho.

Género: animación.

Duración: 11 minutos.

País: Argentina

Año: 2011.

Director: Manuel Quiñones.

Productora: Tembe coop.

Licencia: Creative Commons By-Sazo.

\begin{abstract}
The actions of the English company "The Forestal, Land, Timber and Railways Company limited (1906 -1969) -more popularly known as "La Forestal"- in the Austral Chaco and more specifically in the north of Santa Fe, have generated profound environmental and social impacts with consequences that go beyond the present. As a paradigmatic case, it has been approached in different productions, from literature that became a historiographic record (Gori: 1965) to documentary films that range a whole series of documentaries, the remembered film Quebracho (Wullicher: 1974), and, even more recently it is approached from the animation. This work aims to follow up these productions to focus on the analysis of Viaje a la Tierra del Quebracho (Quiñones: 2011), an animated short film that can be classified at the service of memory. In this case it refers to the dispossession, an identity that struggles to free itself from that imaginary of ghost towns. Not only does it show what happened through fiction and the richness of animated images, but it also takes us back to a historical past with its complexity and consequences while opening us up to many other meanings.
\end{abstract}

Keywords: La Forestal - film productions - memory - dispossession - meanings.

Resumo: O acionar da empresa britânica "The Forestal, Land, Timber and Railways Company limited" (1906-1969) - conhecida mais popularmente como "La Forestal"- no Chaco Austral e mais especificamente no norte de Santa Fe, gerou profundos impactos e ambientais e sociais com consequências que transcendem até hoje. Como caso paradigmático foi abordado em diferentes produções, na literatura que se tornou registro historiográfico (Gori: 1965) às produções cinematográficas que vão desde uma série de documentários ao lembrado filme Quebracho (Wullicher: 1974), até mesmo, mais recentemente, ser abordado a partir da animação. Este trabalho tenciona acompanhar essas produções para concentrar -se na análise de Viaje a la Tierra del Quebracho (Quiñones: 2011), um curta de animação que bem poderia ser classificado como ao serviço da memória, neste caso da espoliação, e 
de uma identidade que luta para libertar-se daquele imaginário de cidades fantasma. Não só mostra o que aconteceu com a ficção e a riqueza das imagens de animação, mas também leva-nos a um passado histórico com sua complexidade e suas conseqüências, enquanto nos abre a muitos outros significados.

Palavras chave: La Forestal - produções fílmicas - memória - espoliação - significados.

[Las traducciones de los abstracts fueron supervisadas por el autor de cada artículo] 